James Madison University JMU Scholarly Commons

Libraries

Libraries \& Educational Technologies

3-17-2015

\title{
Data Information Literacy and Undergraduates: A Critical Competency
}

Yasmeen Shorish

James Madison University, shorisyl@jmu.edu

Follow this and additional works at: http://commons.lib.jmu.edu/letfspubs

Part of the Information Literacy Commons, and the Scholarly Communication Commons

\section{Recommended Citation}

Shorish, Yasmeen, "Data Information Literacy and Undergraduates: A Critical Competency" (2015). Libraries. Paper 27.

http://commons.lib.jmu.edu/letfspubs/27

This Article is brought to you for free and open access by the Libraries \& Educational Technologies at JMU Scholarly Commons. It has been accepted

for inclusion in Libraries by an authorized administrator of JMU Scholarly Commons. For more information, please contact dc_admin@jmu.edu. 


\section{Abstract}

As a primer on data information literacy, this column will cover the background of the field and why it is relevant to college and university libraries serving undergraduate populations. This

Keywords: information literacy, data information literacy, data management, outreach, instruction, higher education, academic libraries, data curation article includes how data information literacy (DIL) relates to information literacy, competencies associated with DIL, the relevance of DIL to undergraduates, DIL in library instruction, and the reasons for library engagement with DIL. Examining DIL within the larger framework of information literacy can help outreach and instruction librarians engage with a format that may be unfamiliar, but whose underlying foundation is well established. 14

\section{(1)}

\section{Introduction}

16

\section{6} meet teaching, learning, and research needs. These information sources have changed format in response to technological advances: incunabula to printed text; print journal articles to PDFs. In addition to providing access to these sources, librarians serve to increase our communities' ability to effectively use this information. As libraries and librarians continue to support scholarship, it is critical to keep abreast of the changes in the scholarly communication landscape, including the role of data as a research source and output. Data traditionally have not

\footnotetext{
1 Physical and Life Sciences Librarian; James Madison University, Rose Library Harrisonburg, VA 22807; shorisyl@jmu.edu
} 
23 been considered a scholarly product to be communicated as a stand alone product. Researchers

24 produce datasets as part of their own research process with little to no intention of sharing them

25 with others, for a variety of reasons (Borgman, Wallis, and Enyedy 2007). However, as research

26 has become increasingly collaborative and networked, data have become more valuable as a

27 scholarly product with potential for reuse. For example, the National Science Foundation (NSF)

28 replaced "publications" with "products" in the instructions for preparing a biographical sketch

29 for a grant proposal, which can include citable and accessible data (National Science Foundation

30 2007, Chapter II.C.2f(c)). Efforts to standardize data citation, such as the Joint Declaration of

31 Data Citation Principles (Force11 n.d.), illustrate how datasets are becoming recognized as

32 standalone scholarly objects. This is especially true in the digital humanities, where the

33 manipulation of existing datasets into new knowledge and new datasets forms the scholarly

34 product of the field (Munoz 2013). As the value of data as a publicly-accessible research output

35 increases, so does the demand for the skills required to make full use of this resource.

36 Considering that funding agencies require data management plans to be submitted with

37 grant applications, and undergraduates are increasingly exposed to the research environment, it is

38 critical that researchers (including students) become fluent in the description, organization, and

39 overall management of research data, including its reuse. Science data literacy has been defined

40 as the ability to collect, process, manage, evaluate, and use data (Qin and D'Ignazio 2010). These

41 can be thought of as the actions of a "data consumer." As we enter more collaborative and

42 interdisciplinary workspaces, it becomes equally important to address the issue of data sharing -

43 the actions of a "data producer." For this reason, Carlson et al (2011) define data information

44 literacy (DIL) as merging "the concepts of researcher-as-producer and researcher-as-consumer,"

45 building upon the foundation of science data literacy, as well as other established literacies that 
46 focus on the consumer side, such as data, statistical, and information literacies (634). Employing

47 these skills enables a researcher to fully engage with every step of the research lifecycle (Fig. 1)

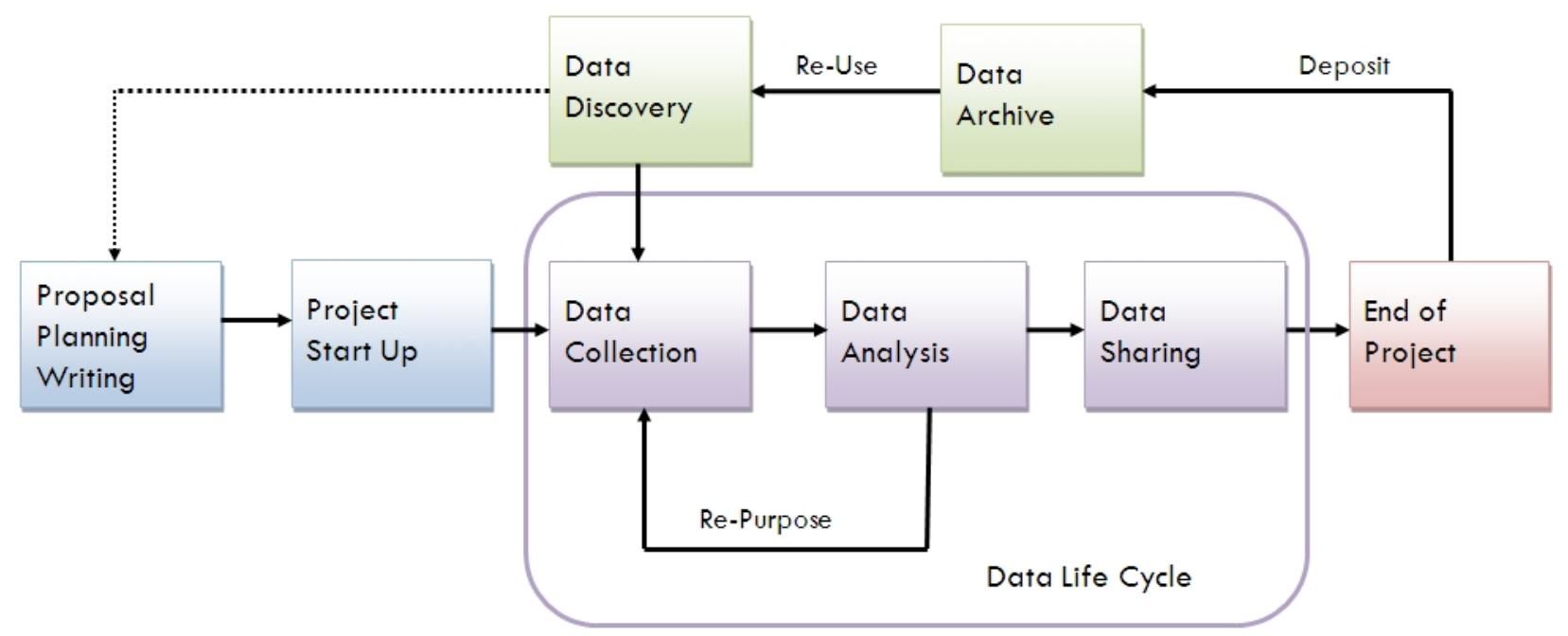

Figure 1: Research Lifecycle (University of Virginia Library n.d.)

Discussions around data sharing and reuse can appear to be limited to issues within "eScience." While e-Science has been defined as a way of conducting scientific research in a collaborative and networked environment (Hey and Hey 2006), there is no reason to limit this methodology to science. Increasingly, research projects are interdisciplinary and data-driven projects are found in the social sciences and humanities (Association of College and Research Libraries: Working Group on Intersections of Scholarly Communication and Information Literacy 2013). Moreover, scientific research is increasingly team-based, distributed, and 57 networked across institutions and nations. Perhaps it is time to drop the term e-Science altogether and acknowledge that technology has changed the way that research occurs. With these changes in technology, it is possible for unanticipated groups to take an interest in one's research data.

For example, an ecologist's data on chemicals found in a waterway may be useful to an 61 epidemiologist tracking environmental factors for a disease. The epidemiologist is not the 62 primary audience for the ecologist, especially if the publication from the data does not highlight 63 a chemical of interest. Nonetheless, the data gathered would be of value to this unintended 
64 audience. With the awareness that data are created in all disciplines and can increasingly be

65 shared electronically and re-used by unintended audiences, the importance of data documentation

66 (Parsons and Duerr 2005) and DIL comes into focus.

\section{The Evolution of Information Literacy and DIL}

69 In order to equip students with the skills that they need to navigate the research landscape, and

70 eventually their professional lives, libraries have engaged in information literacy training.

71 Information literacy addresses how people learn, and gives students skills to "locate, evaluate,

72 and effectively use information for any given need" (Association of College and Research

73 Libraries 1989). Changes in information delivery formats have led to conversations around

74 visual literacy and digital literacy, recognizing that the traditional application of information

75 literacy has not been able to address the nuances of these associated competencies effectively.

76 Our profession recognizes these changes in the scholarly landscape, as evidenced in part

77 by the decision to revise the Association of College and Research Libraries (ACRL) Information

78 Literacy Competency Standards for Higher Education. Approved in 2000, these standards

79 reflected the landscape of higher education at that time (Association of College and Research

80 Libraries 2000). However, higher education is an evolving ecosystem, requiring constant

81 attention. To that end, ACRL has begun to review the information literacy standards and create a

82 new "framework," taking into account changes such as student population demographics,

83 approaches towards student learning and team-based assignments, and the increasing importance

84 of undergraduate research (Association of College and Research Libraries 2014). This new

85 document, Framework for Information Literacy for Higher Education, attempts to take a more 
86 holistic approach towards engagement with information, specifically noting data as a product

87 with which students should gain proficiency.

88 This shift indicates a more intentional treatment of lifelong learning, as the Framework

89 uses threshold concepts to couch activities from the points of view of both the information

90 consumer and the producer. This is in line with the defining characteristic of data information

91 literacy (Carlson et al. 2011), that it equips practitioners with the skills to make data reusable to

92 others in a meaningful way. Data information literacy, with its characteristics of data

93 documentation, preservation, and sharing, requires engagement with a wide array of information

94 skills. To that end, DIL should be treated as any of the other literacy competencies and

95 incorporated into the workflow of outreach librarians, with the acknowledgement that this may

96 require input from other library units, such as metadata and scholarly communication

97 (Association of College and Research Libraries: Working Group on Intersections of Scholarly

98 Communication and Information Literacy 2013).

\section{DIL Competencies}

When thinking about the skills necessary to build data information literacy, it may be

useful to consider the goal outlined in a draft of the forthcoming information literacy framework:

110 The information-consumer language of the original standards has been replaced to illustrate an

111 active, information-producer role. Any DIL competencies should support this effort. 
In the literature, one can find two approaches to DIL that initially appear quite different.

113 The Data Information Literacy project funded by the Institute for Museum and Library Services

114 involved the librarians at Purdue University, the University of Minnesota, Cornell University,

115 and the University of Oregon. That project identified twelve core competencies that cover tool-

116 based areas, such as data processing and analysis, databases, data discovery, data visualization,

117 data quality, and data conversion and interoperability, as well as theory-based areas like data

118 management, data preservation, data curation and reuse, metadata, cultures of practice, and

119 ethics (Carlson et al. 2011). The approach of Calzada Prado and Marzal (2013) detailed five

120 competencies couched in the familiar "understand, find, evaluate, and use" framework shared by

121 ACRL's Information Literacy Competency Standards for Higher Education, with an additional

122 entry for "managing data" (131).

123 Both approaches touch on areas where instruction should occur within the discipline,

124 such as understanding data or analyzing data. These competencies are critical and are best taught

125 by faculty within the context of the subject. The library community could capably address other

126 competencies, such as ethics and preservation. Ethically using information has been foundational

127 to information literacy instruction, often in the form of instruction about citation formatting.

128 While there is currently no body of authority setting DIL standards, the two approaches outlined

129 above provide the DIL community with a foundation upon which to build best practices.

\section{DIL \& Undergraduates}

132 Observations of graduate student behavior at research-intensive universities are

133 analogous to the behavior of undergraduates involved in research at institutions that do not have

134 large graduate populations. While undergraduates may have less experience in research methods, 
135 and may not be involved in as complex research studies (although this is not always true), the

136 "freshness" of the undergraduate offers new opportunities. These students are just beginning to

137 learn and understand research methodology; what better time to introduce data information

138 literacy concepts to their workflow? Carlson and Bracke noted that graduate students at Purdue

139 are involved in the collecting, processing, and analyzing of research data (2013). At colleges and

140 universities with limited or no graduate student population, undergraduates fill this role.

141 Another concern that has been well documented in the data management and data

142 curation literature is the issue of data inheritance (Carlson and Stowell-Bracke 2013; Doucette

143 and Fyfe 2013; Carlson et al. 2013). Faculty direct multi-year research endeavors that can

144 involve multiple cohorts of student research teams through the life of the experiment or project.

145 As a result, work is built upon the data collected and documented by previous students. The

146 amount of time that must be spent translating previous students' notes and processes could be

147 considerable if there were no data management practices in place. Data sets may be opaque to a

148 new student researcher and require mediation by the Principal Investigator (PI), or in the worst-

149 case scenario may be completely unusable.

150 Institutions without a focus in undergraduate research still have a reason to engage with

151 DIL. Carlson et al (2013) found that faculty expected graduate students to possess data

152 management skills before working in their lab, either through prior experience or through their

153 undergraduate education. However, other interviews indicated that faculty found graduate

154 students ill-equipped in this area as the students lacked the skills and training necessary to

155 effectively manage research data (Carlson et al. 2011). Obviously, there is a disconnect between

156 the skills faculty in graduate research labs think students should learn in their undergraduate

157 education and the competencies that those students actually have. 
Data information literacy skills are relevant even if students do not go on to advanced

159 degrees. The majority of individuals receiving post-secondary education in the United States 160 seek a bachelor's degree as their terminal degree. In 2011-12, 1,791,046 bachelor degrees were 161 conferred, more than twice the number of master's degrees and more than ten times the number 162 of doctoral degrees conferred in that same period (Snyder and Dillow 2013). Moreover, these 163 skills are critical to most aspects of business today. An analysis conducted by Gartner, a major 164 information technology research company, found that business leaders, CIOs and compliance 165 officers must adopt data management best practices in order to be cost-effective and agile 166 (Dayley and Childs 2012). A subsequent trend report found that as more businesses rely on data 167 manipulation, so-called "big data" will "become business as usual" (Buytendijk 2014, 1).

168 Therefore, as one seeks to create a more informed and productive citizenry, one should seek to 169 expose all college graduates to the skills required to effectively evaluate and use data.

\section{DIL Instruction}

As with information literacy instruction, there are many different ways to deliver data 173 information literacy instruction to undergraduates. While library-based data management and 174 DIL instruction is relatively recent, it has primarily focused on instruction to graduate students 175 and faculty. This instruction has most often taken the form of seminars or workshops offered 176 through the library as drop-in sessions or one-shot class instruction (Carlson et al. 2013). 177 However, there has been some exploration of instruction at the undergraduate level. In 2008 and 2009, Syracuse University offered an NSF Course, Curriculum, and Laboratory Improvement grant-supported course in science data management (Qin and D'Ignazio 2010). Focused on science data literacy, this course was open to both undergraduates and 
181 graduate students. Qin and D'Ignazio found that the mixed audience class was challenging, as

182 undergraduates had trouble fitting the class into their heavily proscribed schedules and it was

183 difficult to deliver content at a useful level for all students (2010). The University of

184 Massachusetts Medical School and Worcester Polytechnic Institute used funding from the

185 Institute of Museum and Library Services (IMLS) to develop a curriculum framework that would

186 address data management at the undergraduate and graduate levels. By creating modules,

187 delivery to student populations could be tailored based on the experience level and need, since

188 undergraduates may require more modules than graduate students (Piorun et al. 2012). In some

189 environments, it may be most effective to target the instruction to research groups on campus

190 instead of using class time to cover the material. Meeting with research teams on an individual or

191 department level offers an opportunity to discuss in more detail the disciplinary nuances

192 associated with data management. This may help to avoid some of the issues that arose in the

193 Syracuse science data class due to disciplinary disparities.

194 Given the data management requirements of funding agencies, institutions are developing

195 tools and resources. Many of these resources have been created with the PI or graduate student in

196 mind, but there are several ways to adapt them to the undergraduate population. A proposed

197 outcome from the aforementioned IMLS-funded DIL project is a model for librarians to use in

198 developing DIL programs at their own institutions (Purdue University et al. 2013). Updates are

199 posted to the project's website, where one can review handouts and recordings of the sessions

200 from the 2013 DIL Symposium (Purdue University et al. 2013). The Symposium focused on

201 exploring the DIL competencies with librarians and developing strategies for data management

202 engagement with faculty and students. 
Multiple-session DIL courses that can be studied and adapted for the undergraduate 204 student include the University of Minnesota's flipped data management course (Johnston and 205 Jeffryes 2014), the New England Collaborative Data Management Curriculum (Lamar Soutter 206 Library, University of Massachusetts Medical School n.d.), the University of Edinburgh's 207 MANTRA online course (EDINA and Data Library, University of Edinburgh n.d.), and the 208 education modules available from DataONE (DataONE 2012). These are most often presented as 209 sections covering a specific point in the research process, such as defining data, management 210 planning, organizing, and sharing. As discreet units, it is possible to select the sections that are

211 most applicable to an undergraduate student population of varying disciplines who are at 212 different points in their research education.

213 An economics professor and a librarian at Haverford College have developed a protocol 214 for the explicit purpose of teaching data management to undergraduates conducting empirical 215 research (Ball and Medeiros 2012). This approach seeks to encourage students to integrate data 216 management skills into their research practice. Ball and Medeiros suggested that teaching 217 undergraduate students data management as a basic part of research helps assign responsibility 218 and accountability to the findings (2012). This protocol is an exceptional example of how 219 delivering DIL instruction can occur within a discipline's curriculum. Librarians can pair with 220 faculty in their liaison departments to integrate DIL competencies into assignments in much the 221 way that information literacy instruction currently takes place.

\section{Conclusion}


notebooks is considered basic to research training. Students are often told that they should

227 document their notebooks thoroughly enough that anyone could continue work on an experiment

228 from where they stopped, or replicate the steps that they already performed. As more research

229 takes place in the digital realm, there appears to be a disconnect in translating these skills to

230 digital data management.

231 Librarians are often tasked with providing students the training they require to build a

232 practice of lifelong learning. Research and scholarship represent dynamic, evolving processes

233 that occur on a continuum. Understanding that data have the potential to impact not only one's

234 own research, but also the work of others - in fields that may appear unrelated - can help build

235 an awareness of the diverse scholarship ecosystem. As academic librarians prepare students to

236 engage with the world in a meaningful way, it is important that data information literacy not be

237 overlooked. Empowering students to be responsible for the data that they generate, and instilling

238 in them recognition that their data could be used to build further knowledge, should be an

239 integral part of the research process. In order to support this research, libraries must engage with

240 data information literacy for their constituents.

Acknowledgements

243 Thanks to Sharon Weiner, Carolyn Schubert, and Kelly Giles for their feedback on this column.

\title{
References
}

\author{
Association of College and Research Libraries. "Framework for Information Literacy for Higher \\ Education." Association of College and Research Libraries, last modified February 20, 2014, \\ accessed April 2, 2014, http://acrl.ala.org/ilstandards/wp-content/uploads/2014/02/Framework-for- \\ IL-for-HE-Draft-1-Part-1.pdf.
}


- - - . "Information Literacy Competency Standards for Higher Education." Association of College and Research Libraries, accessed April 8, 2014. http://www.ala.org/acrl/standards/informationliteracycompetency.

- - - . "Presidential Committee on Information Literacy: Final Report." Association of College and Research Libraries, last modified January 10, 1989, accessed April 2, 2014. http://www.ala.org/acrl/publications/whitepapers/presidential.

Association of College and Research Libraries: Working Group on Intersections of Scholarly Communication and Information Literacy. 2013. Intersections of Scholarly Communication and Information Literacy: Creating Strategic Collaborations for a Changing Academic Environment. Chicago, IL: Association of College and Research Libraries.

Ball, Richard and Norm Medeiros. 2012. "Teaching Integrity in Empirical Research: A Protocol for Documenting Data Management and Analysis." Journal of Economic Education 43 (2): 182-189. doi:10.1080/00220485.2012.659647. http://www.tandfonline.com/doi/abs/10.1080/00220485.2012.659647.

Borgman, Christine L., Jillian C. Wallis, and Noel Enyedy. 2007. "Little Science Confronts the Data Deluge: Habitat Ecology, Embedded Sensor Networks, and Digital Libraries." International Journal on Digital Libraries 7 (1-2): 17-30.

Calzada Prado, Javier and Miguel Ángel Marzal. 2013. Incorporating Data Literacy into Information Literacy Programs: Core Competencies and Contents. Libri. 63(2): 71-178. doi:10.1515/libri-20130010

Carlson, Jacob, Michael Fosmire, C. C. Miller, and Megan Sapp Nelson. 2011. "Determining Data Information Literacy Needs: A Study of Students and Research Faculty." Portal: Libraries \& the Academy 11 (2): 629-657. http://muse.jhu.edu/journals/portal_libraries_and_the_academy/v011/11.2.carlson.html.

Carlson, Jake, Lisa Johnston, Brian Westra, and Mason Nichols. 2013. "Developing an Approach for Data Management Education: A Report from the Data Information Literacy Project." The International Journal of Digital Curation 8 (1): 204.

Carlson, Jake and Marianne Stowell-Bracke. 2013. "Data Management and Sharing from the Perspective of Graduate Students: An Examination of the Culture and Practice at the Water Quality Field Station." Portal: Libraries \& the Academy 13 (4): 343-361. http://muse.jhu.edu/journals/portal_libraries_and_the_academy/v013/13.4.carlson.html.

DataONE. "DataONE Education Modules." DataONE, accessed April 14, 2014, www.dataone.org/education-modules.

Doucette, Lise and Bruce Fyfe. 2013. "Drowning in Research Data: Addressing Data Management Literacy of Graduate Students." Indianapolis, IN, Assoc. of College and Research Libraries, April 10-13, 2013.

EDINA and Data Library, University of Edinburgh. "Research Data MANTRA [Online Course]." accessed April 14, 2014, http://datalib.edina.ac.uk/mantra. 
Force11. "Joint Declaration of Data Citation Principles." accessed April 14, 2014, https://www.force11.org/datacitation.

Hey, T. and J. Hey. 2006. "E-Science and its Implications for the Library Community." Library Hi Tech 24 (4): 515-528. doi:10.1108/07378830610715383.

Johnston, Lisa R. and Jeffryes, Jon. "Instructor Guide to the Flipped Data Management Course $<b r />$." University of Minnesota Libraries, accessed April 8, 2014, http://z.umn.edu/teachdatamgmt.

Lamar Soutter Library, University of Massachusetts Medical School. "New England Collaborative Data Management Curriculum." accessed April 14, 2014, http://library.umassmed.edu/necdmc.

Munoz, Trevor. 2013. "Data Curation as Publishing for the Digital Humanities." Journal of Digital Humanities 2 (3): 14-22.

National Science Foundation. "Proposal and Award Policies and Procedures Guide: Part 1 - Proposal Preparation \& Submission Guidelines (GPG)." National Science Foundation.

Parsons, M.,A. and R. Duerr. 2005. "Designating User Communities for Scientific Data: Challenges and Solutions." Data Science Journal 4: 31-38.

Piorun, Mary, Donna Kafel, Tracey Leger-Hornby, Siamak Najafi, Elaine Martin, Paul Colombo, and Nancy LaPelle. 2012. "Teaching Research Data Management: An Undergraduate/Graduate Curriculum." Journal of eScience Librarianship 1 (1): 46-50. doi:10.7191/jeslib.2012.1003. http://escholarship.umassmed.edu/jeslib/vol1/iss1/8.

Purdue University, University of Minnesota, University of Oregon and Cornell University. "Data Information Literacy." accessed April 14, 2014, http://wiki.lib.purdue.edu/display/ste/Home.

Qin, Jian and John D'Ignazio. 2010. Lessons Learned from a Two-Year Experience in Science Data Literacy Education. http://docs.lib.purdue.edu/iatul2010/conf/day2/5.

Snyder, T. D. and S. A. Dillow. 2013. Digest of Education Statistics 2012 (NCES 2014-015). Washington, DC.: National Center for Education Statistics, Institute of Education Sciences, U.S. Department of Education.

University of Virginia Library. "Steps in the Research Life Cycle." accessed April 16, 2014, http://dmconsult.library.virginia.edu/lifecycle/. 